\title{
Mejora en la eficiencia y en el ambiente de trabajo en Texgroup S.A.
}

\author{
Jhosselyn Herrera* \\ Universidad de Lima \\ Recibido: 14 de mayo del 2018 / Aprobado: 1 de junio del 2018 \\ doi: 10.26439/ing.ind2018.n036.2445
}

\begin{abstract}
RESUMEN: La mejora continua representa una oportunidad para incrementar la competitividad y alinear los procesos hacia una producción libre de desperdicio y de alto valor para los clientes de una compañía, lo cual fue analizado y demostrado en la compañía Texgroup S.A., en la que, a través del uso de metodologías como la de los siete pasos, se consiguió mejorar la eficiencia operativa y el ambiente de trabajo.
\end{abstract}

Palabras clave: industria de la confección / eficiencia industrial / productividad

\section{Improvement on the efficiency and work environment at Texgroup S.A.}

\begin{abstract}
Continuous improvement represents an opportunity to increase competitiveness and to adjust processes towards a waste-free production, which is highly valuable for the customers of a company. These aspects were analyzed and demonstrated at the company Texgroup S.A., where the operational efficiency and work environment were upgraded using methodologies such as the 7-Step Improvement Process.
\end{abstract}

Keywords: clothing industry / industrial efficiency / productivity

* Correo electrónico: jhosselyn.herrera@gmail.com 


\section{ANTECEDENTES DE LA EMPRESA}

Texgroup S.A. es una empresa peruana que desde el año 1995 se dedica a la fabricación de prendas de vestir en tejido plano y de punto para el mercado internacional. Pertenece a la Corporación Cervesur, conglomerado de importantes empresas de distintos sectores productivos y de servicios. El proceso productivo de Texgroup es llevado a cabo en una planta de $15000 \mathrm{~m}^{2}$ ubicada en el distrito de Ate, donde se realiza el desarrollo, el corte, la costura y el acabado de alrededor de 1,8 millones de prendas al año.

\section{METODOLOGÍA}

La metodología utilizada fue la de los siete pasos de la mejora continua, la cual, además de ser una hoja de ruta para llevar a cabo un proyecto, ofrece la ventaja de hacerlo permanente y mejorable por sí mismo. Al ser un proyecto que mejora la productividad de una compañía industrial de mano de obra intensiva, es necesario que cualquier mejora vaya enfocada en obtener el máximo retorno posible mediante la racionalización de los recursos.

Del desglose del costo total de una prenda, se obtiene lo siguiente:

Tabla 1

Participación de los principales inyectores de gasto

\begin{tabular}{lc} 
Concepto & Participación \\
\hline $\begin{array}{l}\text { Costo de manufactura (mano de obra + maquinaria + } \\
\text { servicios generales) }\end{array}$ & $50 \%$ \\
$\begin{array}{l}\text { Costo de materiales de confección (tela + avíos) } \\
\text { Gastos administrativos y ventas (adheridos al servicio } \\
\text { de confección }{ }^{*} \text { ) }\end{array}$ & $55 \%$ \\
\hline
\end{tabular}

Fuente: SNI (2014)

En ese sentido, el costo de manufactura representa el mayor porcentaje de participación en los costos de proceso, por lo que cualquier mejora o ahorro en este tendrá un mayor impacto sobre la utilidad de la compañía. 


\section{DESARROLLO DE LA METODOLOGÍA DE LOS 7 PASOS DE LA MEJORA CONTINUA}

\section{PASO 1: Seleccionar el problema \\ Selección del proceso por mejorar}

Dentro de la estructura de costos de manufactura están los de mano de obra de los procesos de corte, costura y acabado.

A continuación, se muestra la distribución del personal de la compañía, y se observa que el grueso de los colaboradores se encuentra en la parte productiva:

Tabla 2

Distribución de personal

\begin{tabular}{llcc}
\hline Personal & & Cantidad & $\begin{array}{c}\text { Participación } \\
(\%)\end{array}$ \\
\hline \multirow{3}{*}{ Operarios } & Producción (Corte/costura/acabados) & 842 & \\
& Muestras & 60 & 88 \\
& Control de calidad & 110 & \\
& Limpieza & 12 & 12 \\
\hline \multirow{2}{*}{ Empleados } & & 120 & 100 \\
\hline
\end{tabular}

Fuente: Texgroup S.A. (2014)

\section{Determinación y descripción del proceso}

El proceso productivo comienza en el área de corte, donde se realiza el tendido de la tela, corte en piezas, fusionado, numerado y habilitado. Luego, la costura se divide en dos: preparado y ensamble. El primero consiste en la confección de cuellos, puños y delanteros, y la segunda etapa es el ensamble de las demás piezas junto a estos. Luego los lotes son sometidos a una auditoría y transportados al área de acabados, la cual se encarga del soplado, planchado, doblado, acomodo, embolsado y encajado. Finalmente, las prendas son trasladadas a un último control de calidad y son ubicadas en el Almacén de Productos Terminados. 


\section{Identificación de los problemas principales}

Para identificar los problemas principales de la compañía, se utilizó la herramienta de calidad "VOC: Voz del cliente", donde se entrevistó a la alta dirección, la cual está conformada por seis gerentes: gerente general, gerente administrativo y de finanzas, gerente comercial tejidos y prendas, gerente comercial hilado, gerente técnico de hilados y tejidos, y gerente técnico de confecciones.

La entrevista consistió en tres principales aspectos: tiempo, calidad y costos. A continuación se muestra el listado de problemas que detallaron los gerentes:

Tabla 3

Resumen de comentarios de gerencia técnica de Texgroup S.A.

\begin{tabular}{|c|c|c|}
\hline Variable & \multicolumn{2}{|r|}{ Problema } \\
\hline \multirow{7}{*}{ Tiempo } & T1 & $\begin{array}{l}\text { La cotización de prendas toma muchos días y recursos y retrasa el } \\
\text { inicio de la confección. }\end{array}$ \\
\hline & & $\begin{array}{l}\text { Dentro del lead time to market, el tiempo de cotización y } \\
\text { preproducción es mayor al asignado a producción. }\end{array}$ \\
\hline & T2 & Tiempo de atención de almacenes de avíos y telas. \\
\hline & & $\begin{array}{l}\text { El almacén de avíos tiene tiempos de búsqueda mayores a los de } \\
\text { habilitado efectivo. }\end{array}$ \\
\hline & & $\begin{array}{l}\text { La tela asignada para la última etapa de la preproducción llega } \\
\text { junto a la tela de producción, lo cual retrasa el inicio del corte, pues, } \\
\text { si bien la tela está disponible, esta no puede ser usada hasta ser } \\
\text { liberada por DDP. }\end{array}$ \\
\hline & T3 & $\begin{array}{l}\text { La definición oportuna de avíos de confección es necesaria para evitar } \\
\text { retrasos en el inicio de la confección. }\end{array}$ \\
\hline & & $\begin{array}{l}\text { La definición de avíos puede extenderse hasta más de } 30 \text { días } \\
\text { antes del inicio de la confección, al considerar que este periodo } \\
\text { es equivalente al lead time de los proveedores. Frecuentemente la } \\
\text { llegada de estos marca el inicio de la costura hasta después de la } \\
\text { fecha programada. }\end{array}$ \\
\hline
\end{tabular}

(continúa) 
(continuación)

\begin{tabular}{|c|c|c|}
\hline Variable & \multicolumn{2}{|r|}{ Problema } \\
\hline \multirow{7}{*}{ Calidad } & Q1 & Los estándares de calidad deben respetarse al $100 \%$. \\
\hline & & $\begin{array}{l}\text { Los estándares de confección de la compañía, si bien están } \\
\text { establecidos, no son de conocimiento de todo el personal (con } \\
\text { mayor incidencia en personal con menos de } 3 \text { meses), lo cual } \\
\text { genera distorsiones en el criterio de evaluación del producto } \\
\text { conforme. }\end{array}$ \\
\hline & Q2 & $\begin{array}{l}\text { Los supervisores deben responsabilizarse al } 100 \% \text { de la calidad de } \\
\text { su proceso. }\end{array}$ \\
\hline & & $\begin{array}{l}\text { El personal de supervisión está acostumbrado a que su trabajo sea } \\
\text { revisado posteriormente al } 100 \% \text {, lo cual genera el paradigma de } \\
\text { que los defectos deben encontrarse, mas no prevenirse. }\end{array}$ \\
\hline & Q3 & Los reclamos posventa por calidad se encuentran fuera de control. \\
\hline & & $\begin{array}{l}\text { Los rechazos en auditorías en destino, principalmente con clientes } \\
\text { nuevos, reducen la posibilidad de futuros pedidos. }\end{array}$ \\
\hline & Q4 & $\begin{array}{l}\text { Los reprocesos generan muchas horas de paro que son compensadas } \\
\text { con sobretiempo. }\end{array}$ \\
\hline & & $\begin{array}{l}\text { Los reprocesos posteriores a la clasificación del producto no } \\
\text { conforme generan una gran cantidad de minutos trabajados, pero } \\
\text { no producidos. }\end{array}$ \\
\hline Costos & C1 & $\begin{array}{l}\text { Las eficiencias de la planta deben aumentar para incrementar el } \\
\text { margen. }\end{array}$ \\
\hline & & $\begin{array}{l}\text { Se ha calculado que la eficiencia que satisface la mínima expectativa } \\
\text { de los accionistas sin dejar utilidad disponible para reinvertir es de } \\
65 \% \text {. }\end{array}$ \\
\hline & $\mathbf{C 2}$ & $\begin{array}{l}\text { El control de las mermas debe ser exhaustivo para conocer su impacto } \\
\text { económico. }\end{array}$ \\
\hline & & $\begin{array}{l}\text { Las frecuentes compras para mejorar fechas de entrega o no } \\
\text { detener los módulos de costura generan excedentes en los } \\
\text { almacenes que no pueden ser utilizados posteriormente, pues son } \\
\text { compras a pedido para temporadas específicas. }\end{array}$ \\
\hline & C3 & Dependencia de la mano de obra calificada. \\
\hline & & $\begin{array}{l}\text { Al ser una industria de mano de obra intensiva, se requiere personal } \\
\text { entrenado en el uso de máquinas y métodos de confección } \\
\text { industrial. }\end{array}$ \\
\hline
\end{tabular}

Nota: Aplicación de VOC a gerentes de la compañía Elaboración propia

Para la evaluación y la ponderación de los factores, se usará la matriz de enfrentamiento. 


\begin{tabular}{|c|c|c|c|c|c|c|c|c|c|c|c|c|}
\hline & $\begin{array}{l}\frac{0}{0} \\
\frac{\pi}{2} \\
\frac{0}{0} \\
0 \\
0 \\
0\end{array}$ & $\frac{n}{\text { i }}$ & 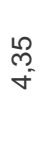 & $\frac{N}{\text { s }}$ & 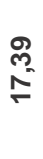 & $\begin{array}{l}\dot{J} \\
\stackrel{m}{\leftarrow}\end{array}$ & 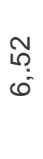 & $\begin{array}{l}\hat{\infty} \\
\infty \\
0 \\
-\end{array}$ & $\begin{array}{l}\text { N్} \\
\text { เి }\end{array}$ & $\frac{\rho}{\infty^{\circ}}$ & $\begin{array}{l}\text { م⿱⺊口 } \\
\text { ô }\end{array}$ & \\
\hline & $\begin{array}{l}\bar{\pi} \\
\text { 음 }\end{array}$ & $\tau$ & $\sim$ & - & $\infty$ & 0 & $m$ & ما & $\wedge$ & $\nabla$ & $\sigma$ & Q \\
\hline & $\mathcal{O}$ & 0 & 0 & 0 & 0 & 0 & 0 & 0 & 0 & 0 & & \\
\hline & ชิ & 0 & 0 & 0 & - & - & 0 & - & - & & - & \\
\hline & $\overline{0}$ & 0 & 0 & 0 & $\tau$ & 0 & 0 & 0 & & 0 & $\tau$ & \\
\hline & ठ & 0 & 0 & 0 & $\tau$ & - & 0 & & - & 0 & - & \\
\hline & ช̊ & 0 & 0 & 0 & - & - & & $\tau$ & $r$ & - & $r$ & \\
\hline & ชี & 0 & 0 & 0 & - & & 0 & 0 & $r$ & 0 & - & \\
\hline & $\bar{\sigma}$ & 0 & 0 & 0 & & 0 & 0 & 0 & 0 & 0 & $r$ & \\
\hline \multirow{4}{*}{ 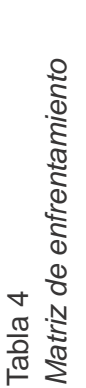 } & $\stackrel{m}{\mapsto}$ & - & - & & $\tau$ & $r$ & $\tau$ & - & $r$ & - & - & \\
\hline & $\stackrel{\sim}{\sim}$ & 0 & & 0 & - & - & - & - & - & - & - & \multirow{3}{*}{$\begin{array}{l}\frac{\pi}{0} \\
\frac{0}{0} \\
: \frac{0}{0} \\
\frac{\pi}{\square} \\
\frac{0}{\square}\end{array}$} \\
\hline & $F$ & & - & - & - & - & - & - & - & - & - & \\
\hline & 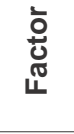 & $F$ & $\stackrel{\sim}{\vdash}$ & $\stackrel{m}{\models}$ & $\overline{0}$ & ชี & రి & ర & $\overline{0}$ & ช & $\mathcal{O}$ & \\
\hline
\end{tabular}


Del análisis anterior, se obtiene que los factores más relevantes son la dependencia de la mano de obra calificada (19,57 \%), la eficiencia de planta (17,39 \%) y el cumplimiento de los estándares de calidad (15,22 \%).

Con respecto a la mano de obra calificada, esta solo se puede retener al incrementar la parte variable del salario de los trabajadores, la cual sube o baja en función de la eficiencia lograda por los equipos de trabajo. Adicionalmente, la eficiencia de costura es el principal indicador de planta y afecta directamente a la utilidad de la compañía; por lo tanto, cualquier intento de mejora se verá reflejado en los resultados al final de cada periodo. Y, por último, el cumplimiento al $100 \%$ de los estándares de calidad es indispensable para la continuidad del flujo de costura; sin embargo, según los resultados de la última auditoría interna de ISO 9001 , solo el $60 \%$ del personal sabe y aplica los procedimientos y las instrucciones de trabajo. Esto se debe principalmente a la alta rotación de personal ( $6 \%$ mensual en promedio).

Llegado a este punto, el problema más resaltante e integral es la baja eficiencia en planta, porque, al lograr mejorar algunos puntos de eficiencia, indirectamente también se resuelven los otros dos problemas principales: se incrementa el salario y, por ende, se reduce la rotación.

\section{PASO 2: Clarificar y subdividir el problema}

\section{Determinación de las causas raíces de los problemas seleccionados}

Con la información recopilada y analizada hasta el momento, se puede observar que existen oportunidades de mejora que representarían un gran impacto en los medios de producción de Texgroup S.A.

Como primera parte de la planificación, se preparó un breve informe de los datos recopilados sin interpretación, el cual fue distribuido al gerente técnico y a los jefes de área, junto a una invitación a una serie de reuniones para identificar las posibles alternativas de solución a los problemas principales.

Para que las reuniones se puedan llevar a cabo de forma objetiva, se decidió utilizar la metodología Sedac, herramienta de calidad que permite facilitar la resolución de problemas de productividad sistemáticamente mediante el análisis de sus causas raíces. 
El desarrollo de la dinámica Sedac se realizó en cuatro sesiones con un espacio de una semana entre ellas, con una duración de tres horas. Participaron los gerentes y jefes de la planta de confecciones.

Para el desarrollo de la metodología, es necesario el uso de tarjetas rojas, amarillas y verdes. Las primeras se usan para los problemas o las causas que afectan el indicador; las segundas, solo en caso la causa sea compleja o se necesite cuantificar; y las terceras son tarjetas de soluciones.

En el desarrollo de la primera reunión, se entregaron tarjetas de cada color en blanco a cada miembro y la lista de causas raíces brindada sobre la información recopilada.

Seguidamente, los participantes escribieron en las tarjetas rojas y las colocaron por afinidad en el tablero Sedac. Las afinidades disponibles eran afinidad 1: planeamiento y programación; afinidad 2: personal operario y empleado; afinidad 3: materias primas y materiales; y afinidad 4: información y métodos. Una vez elegida la afinidad se procedía a su lectura en grupo y explicación del por qué ese problema fue seleccionado y va en esa categoría.

En la segunda reunión, cada integrante pudo armar su tablero Sedac personal para posteriormente, en la tercera reunión, en discusión grupal, generar el tablero general con las afinidades asignadas a cada causa raíz determinada por consenso, donde los integrantes discutieron si era necesario cuantificar a fondo alguna causa mediante el uso de las tarjetas amarillas.

Finalmente, en las tarjetas verdes, colocaban las posibles soluciones, las cuales eran revisadas en grupo también hasta llegar a un acuerdo con una cantidad de soluciones mayor o igual al número de causas raíces.

Con el tablero general ya elaborado, en la cuarta reunión se presentó un informe a modo de resumen con los puntos en los que los participantes tuvieron mayor incidencia. A continuación, se muestra el panel Sedac: 
Mejora en la eficiencia y en el ambiente de trabajo en Texgroup S.A.

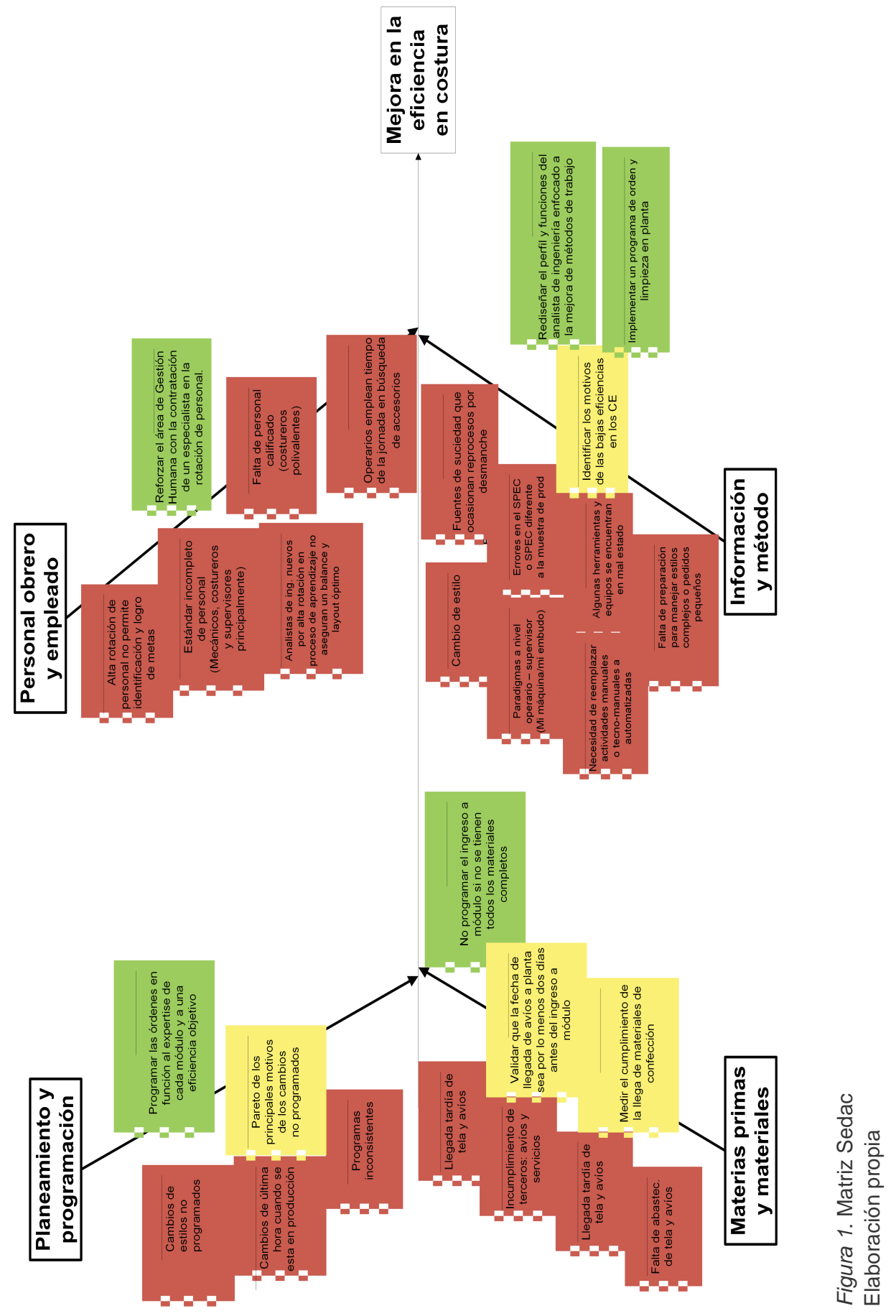




\section{PASO 3: Analizar las causas de su raíz}

Se realizó un análisis en planta, para lo cual se diseñó un formato donde se detallan todas las interferencias y/o paradas en producción más recurrentes. Si bien se conocen estas, no están cuantificadas. Este formato contempla el área responsable, el motivo de la interferencia y tiene un horizonte de información de una semana.

Tabla 5

Detalle de interferencias

\begin{tabular}{|c|c|c|c|}
\hline Área & Interferencia & Código & Descripción \\
\hline DDP & Mal tizado & DDP1 & $\begin{array}{l}\text { Cuando la distribución de las piezas no } \\
\text { se ajusta a las características del tejido. }\end{array}$ \\
\hline DDP & Error spec & DDP2 & $\begin{array}{l}\text { La información técnica no es suficiente o } \\
\text { no es factible. }\end{array}$ \\
\hline DDP & Error marcador & DDP3 & $\begin{array}{l}\text { Los patrones de cartón para referencia } \\
\text { de medidas no están correctos. }\end{array}$ \\
\hline DDP & Ingreso muestras & DDP4 & $\begin{array}{l}\text { Por falta de capacidad de la sala de } \\
\text { muestras, se ingresan muestras a pro- } \\
\text { ducción. }\end{array}$ \\
\hline DDP & Falla medidas & DDP5 & $\begin{array}{l}\text { Las medidas de las piezas no permiten } \\
\text { coser de acuerdo con la especificación. }\end{array}$ \\
\hline DDP & $\begin{array}{l}\text { Información } \\
\text { incompleta }\end{array}$ & DDP6 & $\begin{array}{l}\text { La información necesaria para arrancar } \\
\text { un estilo no está completa. }\end{array}$ \\
\hline Corte & Falla corte & CRT1 & Error en el proceso de corte. \\
\hline Corte & Desabastecimiento & CRT2 & $\begin{array}{l}\text { La orden de producción ha salido fuera } \\
\text { de tiempo hacia costura. }\end{array}$ \\
\hline Corte & $\begin{array}{l}\text { Tela fallada/cambio } \\
\text { de piezas }\end{array}$ & CRT3 & $\begin{array}{l}\text { Las piezas presentan fallas que no han } \\
\text { sido detectadas al momento del corte. }\end{array}$ \\
\hline Terceros & Desabastecimiento & TRC1 & $\begin{array}{l}\text { Abastecimiento tardío de los servicios de } \\
\text { bordado/estampado. }\end{array}$ \\
\hline Terceros & Falla & TRC2 & $\begin{array}{l}\text { El producto entregado por el proveedor } \\
\text { no cumple lo especificado. }\end{array}$ \\
\hline PCP & Cambio de programa & PCP1 & $\begin{array}{l}\text { El programa de producción ha sido } \\
\text { modificado repentinamente. }\end{array}$ \\
\hline PCP & Error en liquidación & PCP2 & $\begin{array}{l}\text { Se ha producido un error en la liquidación } \\
\text { (balance) de tela. }\end{array}$ \\
\hline PCP & Avío faltante & PCP3 & $\begin{array}{l}\text { Los avíos no han llegado a la planta } \\
\text { en el tiempo requerido para el inicio de } \\
\text { costura. }\end{array}$ \\
\hline
\end{tabular}

(continúa) 
(continuación)

\begin{tabular}{|c|c|c|c|}
\hline Área & Interferencia & Código & Descripción \\
\hline PCP & Avío mal asignado & PCP4 & Error en la compra de avíos. \\
\hline Calidad & Desbalances & CAL1 & $\begin{array}{l}\text { Falta de inspectores o auditores en } \\
\text { planta. }\end{array}$ \\
\hline Calidad & $\begin{array}{l}\text { Definición de } \\
\text { criterios }\end{array}$ & CAL2 & $\begin{array}{l}\text { No se define la liberación/rechazo de un } \\
\text { producto. }\end{array}$ \\
\hline Calidad & Rechazo tardío & CAL3 & $\begin{array}{l}\text { Se ha rechazado un producto en una } \\
\text { etapa posterior en la que ha sido } \\
\text { aceptado. }\end{array}$ \\
\hline Calidad & Avío defectuoso & CAL4 & $\begin{array}{l}\text { Avíos ingresados al almacén con el } \\
V .^{\circ} \mathrm{B} .^{\circ} \text { de calidad no están de acuerdo } \\
\text { con lo especificado. }\end{array}$ \\
\hline RR.HH & Personal faltante & $\mathrm{RH} 1$ & $\begin{array}{l}\text { Reclutamiento no completa los } \\
\text { requerimientos pendientes. }\end{array}$ \\
\hline Producción & $\begin{array}{l}\text { Incumplimiento de } \\
\text { spec }\end{array}$ & PRD1 & $\begin{array}{l}\text { No se ha cumplido lo indicado en la } \\
\text { especificación. }\end{array}$ \\
\hline Producción & Reproceso & PRD2 & $\begin{array}{l}\text { Reprocesos realizados en las horas de } \\
\text { trabajo regulares. }\end{array}$ \\
\hline Producción & $\begin{array}{l}\text { Vacaciones sin } \\
\text { coordinación }\end{array}$ & PRD3 & $\begin{array}{l}\text { Se han programado vacaciones de } \\
\text { manera repentina. }\end{array}$ \\
\hline Producción & Ausentismo & PRD4 & Ausencia de trabajadores. \\
\hline Producción & $\begin{array}{l}\text { Desabastecimiento } \\
\text { de cuellos/puños }\end{array}$ & PRD5 & $\begin{array}{l}\text { Cuellos y puños no cumplen con } \\
\text { especificación o presentan retraso en } \\
\text { entrega. }\end{array}$ \\
\hline Producción & Tiraje corto & PRD6 & $\begin{array}{l}\text { Órdenes de producción menores a } 600 \\
\text { prendas. }\end{array}$ \\
\hline Ingeniería & $\begin{array}{l}\text { Sin máquina/ } \\
\text { accesorios }\end{array}$ & ING1 & $\begin{array}{l}\text { Falla en la disponibilidad de máquinas o } \\
\text { accesorios. }\end{array}$ \\
\hline Ingeniería & $\begin{array}{l}\text { Operario nuevo/baja } \\
\text { eficiencia }\end{array}$ & ING2 & $\begin{array}{l}\text { Operario no ha completado la curva de } \\
\text { aprendizaje. }\end{array}$ \\
\hline Ingeniería & Máquina malograda & ING3 & $\begin{array}{l}\text { Máquina en mal estado de } \\
\text { funcionamiento. }\end{array}$ \\
\hline Ingeniería & $\begin{array}{l}\text { Tiempo mal } \\
\text { estimado }\end{array}$ & ING4 & Tiempo estándar no se ajusta al real. \\
\hline Ingeniería & $\begin{array}{l}\text { Calibración de } \\
\text { máquina }\end{array}$ & ING5 & Máquina requerida no está calibrada. \\
\hline Ingeniería & $\begin{array}{l}\text { Regulación por } \\
\text { cambio de estilo }\end{array}$ & ING6 & $\begin{array}{l}\text { Movimiento de personal/máquinas por } \\
\text { cambio de estilo. }\end{array}$ \\
\hline
\end{tabular}

Elaboración propia 


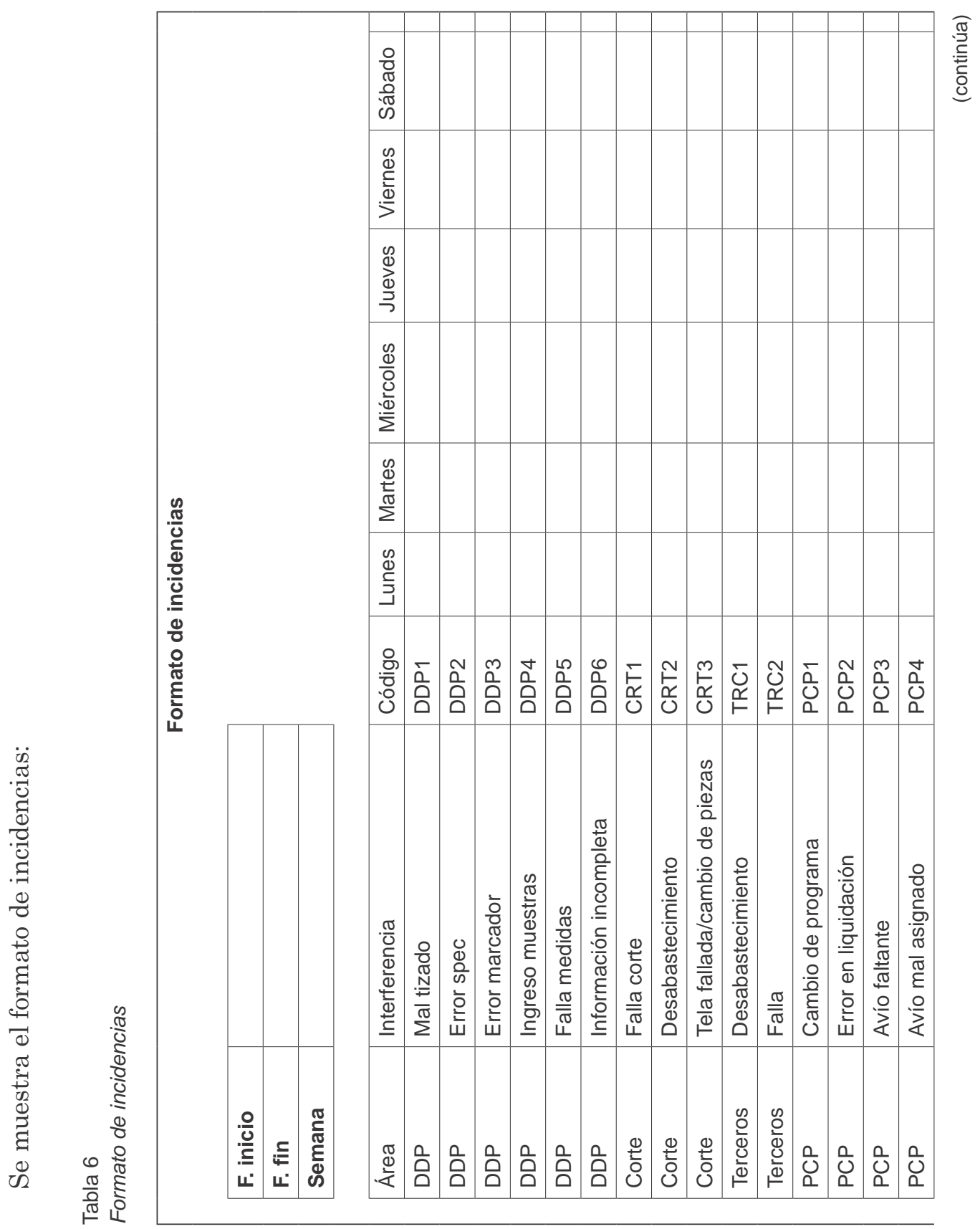




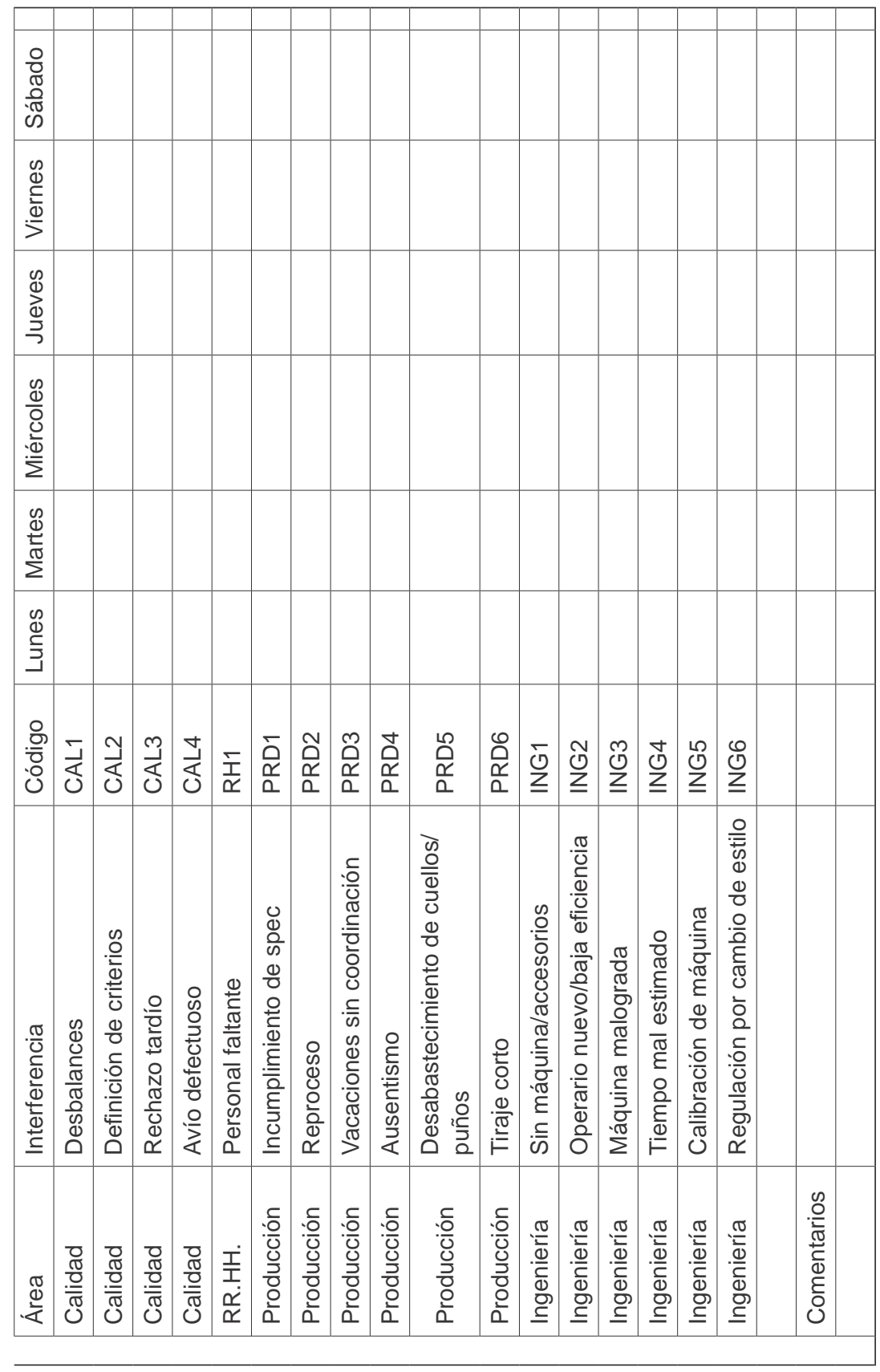


El formato fue usado en el 2014 y, para términos de esta investigación, solo se tomarán en cuenta cinco meses elegidos aleatoriamente. La información es registrada diariamente por las supervisoras de cada módulo y es tabulada por el departamento de ingeniería al terminar la semana. Esta misma técnica fue usada para recopilar la información de cinco meses, y los resultados fueron los siguientes:

Tabla 7

Resumen de interferencias por área

\begin{tabular}{lc}
\hline \multicolumn{1}{c}{ Área } & Interferencia \\
\hline DDP & 77 \\
Corte & 247 \\
Terceros & 117 \\
PCP & 14 \\
Calidad & 44 \\
RR. HH. & 0 \\
Producción & 502 \\
Ingeniería & 615 \\
\hline
\end{tabular}

Elaboración propia

Para el análisis de datos, se usó el diagrama de Pareto para identificar las principales interferencias.

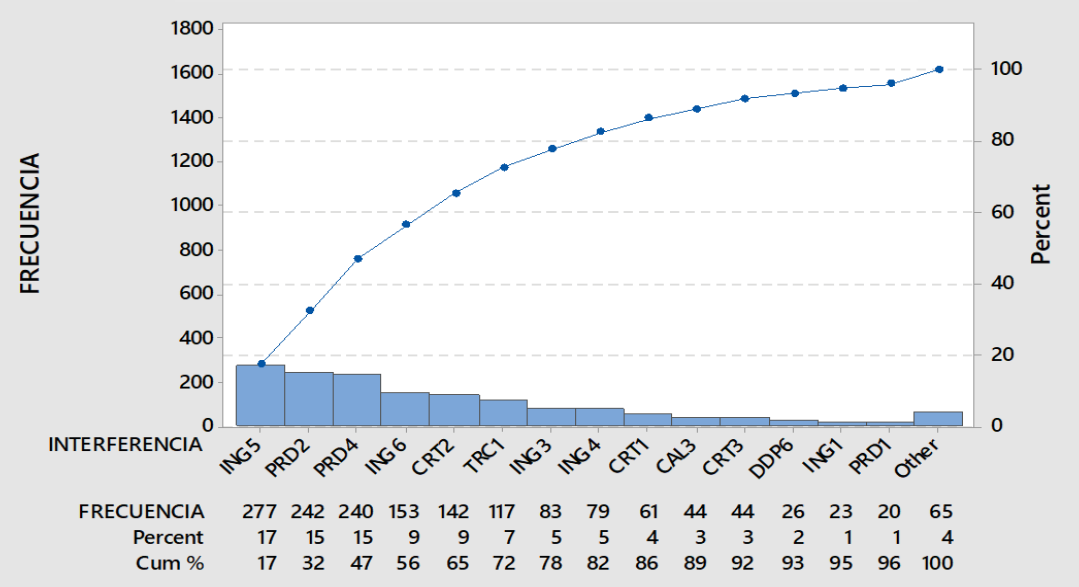

Figura 2. Diagrama de Pareto de interferencias Elaboración propia 
Del análisis anterior, se obtuvo como resultado que las interferencias ING 5 (calibración de máquina), PRD2 (reprocesos) y PRD4 (ausentismo) representan el $50 \%$ del total de interferencias registradas en el periodo, con lo cual se infiere que su reducción representaría automáticamente la reducción en la mitad del tiempo. Asimismo, se replicó el análisis en función de las áreas responsables de la solución de cada interferencia.

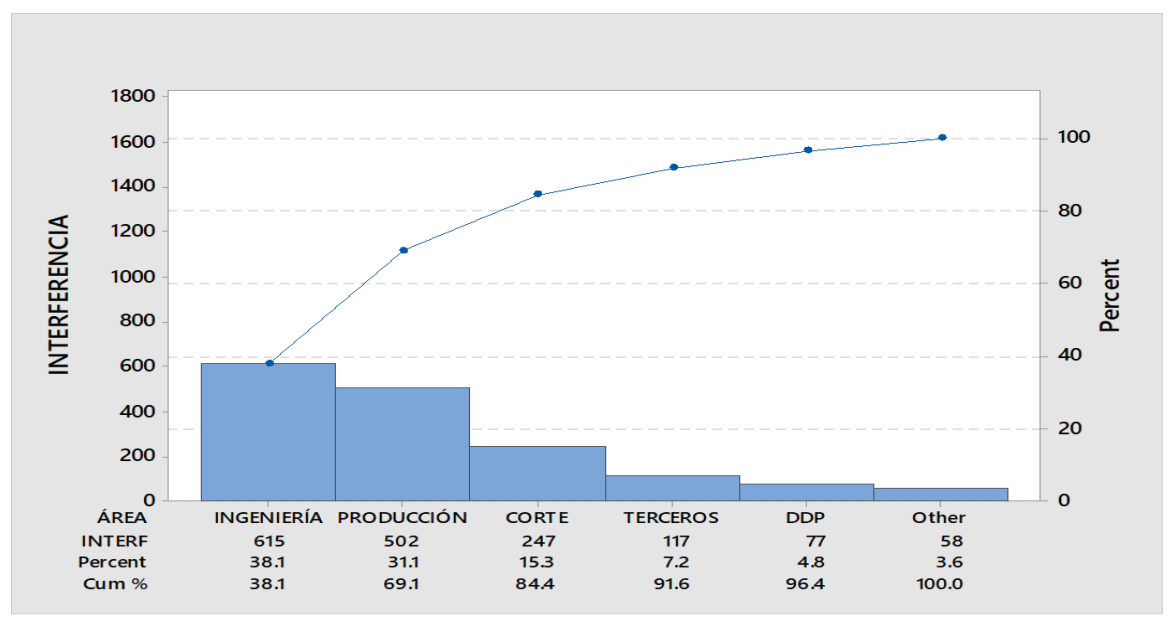

Figura 3. Diagrama de Pareto de interferencias por área Elaboración propia

Como resultado del análisis de incidencias, se obtuvo que las áreas de ingeniería y producción son responsables del $70 \%$ del total de interferencias.

Seguidamente, para ubicar las causas raíces atribuidas a cada interferencia mayor, se realizaron diagramas de causa y efecto (Figura 4).

Para la primera interferencia mayor ING5, relacionada con la calibración de máquinas y el tiempo que esta operación podría tomar, el cual en el caso de extenderse, afecta directamente al incremento del tiempo improductivo. Esta tarea es de responsabilidad del mecánico del módulo de costura, bajo la instrucción del analista de ingeniería, quien define y provee el equipo a usar y sus accesorios. Por lo tanto, el efecto se determina como la demora en la calibración de máquina.

Sobre la base de las causas de la interferencia ING5, se realizó un análisis cuantitativo con el uso y el registro de un formato de causas.

El siguiente formato fue usado durante un mes en todos los módulos de costura a cargo del supervisor (Tabla 9). 

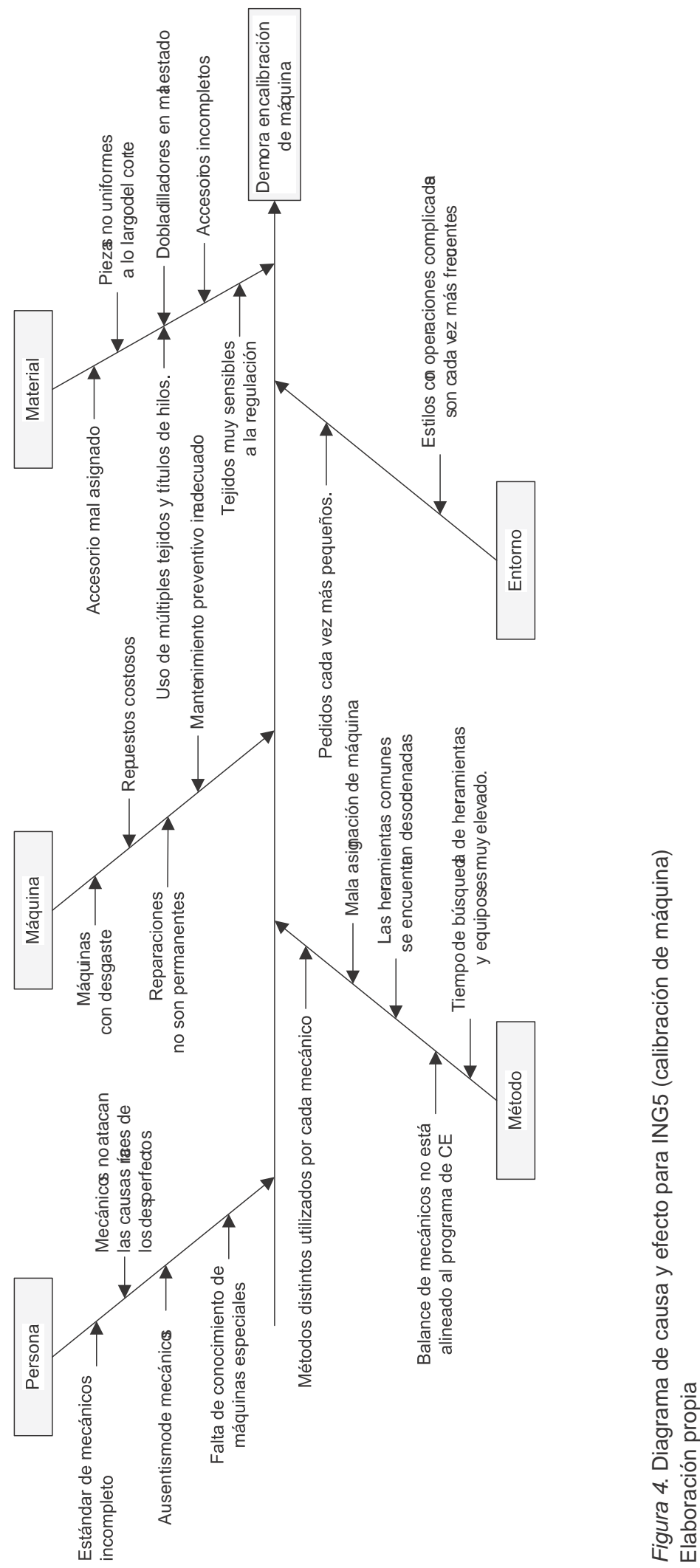

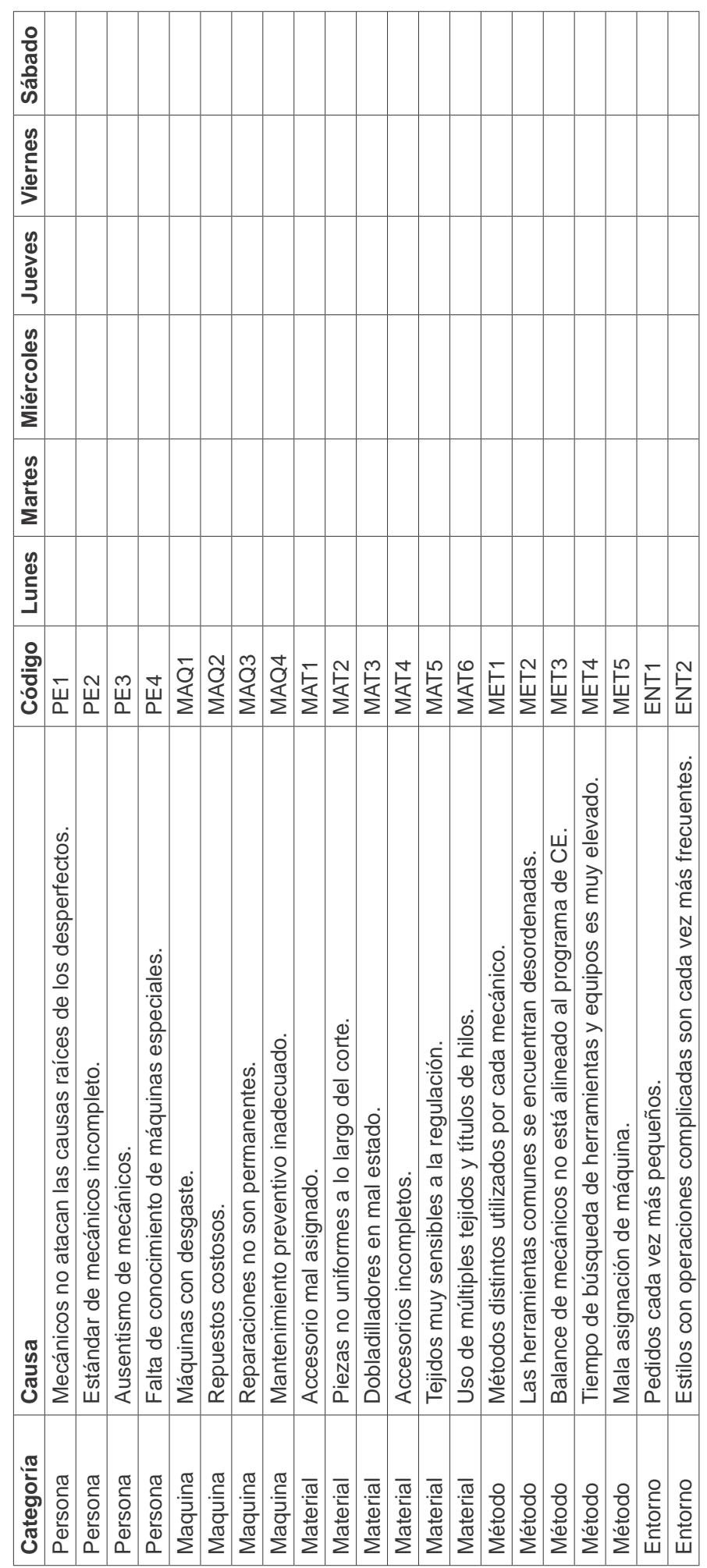

$\infty \underset{\pi}{\pi}$

흔

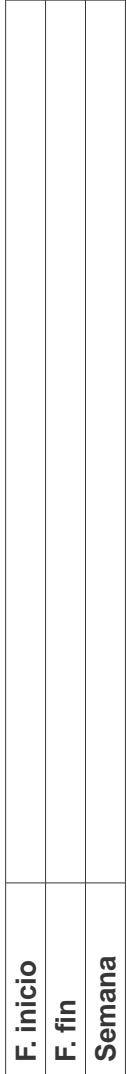


La información es registrada diariamente por el departamento de ingeniería y tabulada al terminar la semana. Del resumen de la tabulación se obtuvo el siguiente diagrama de Pareto:

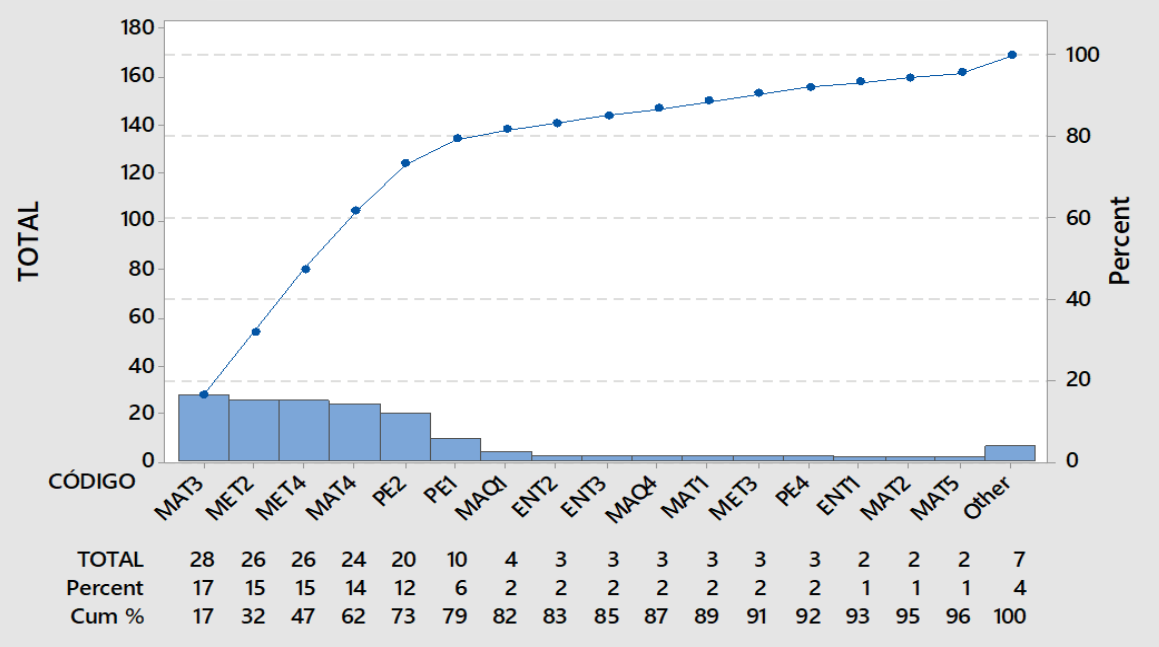

Figura 5. Diagrama de Pareto de causas - ING5 Elaboración propia

Se puede observar que las principales causas raíces son MAT3, MET2, MET4 y MAT4, las cuales corresponden a dobladilladores en mal estado, herramientas comunes en mal estado, tiempo de búsqueda de herramientas y equipos muy elevado y accesorios incompletos, las cuatro con un porcentaje acumulado de alrededor del $62 \%$ de participación como causas del problema principal.

Para la segunda interferencia mayor PRD2, relacionada con los reprocesos y los recursos (h-h, avíos, tela, productos químicos, etc.) que esta operación podría tomar, en el caso de extenderse, afecta directamente al incremento del tiempo improductivo. Esta interferencia es responsabilidad del supervisor, ya que es el encargado de revisar cada operación del flujo de proceso. Por lo tanto, a continuación, se detallarán las causas de los reprocesos: 


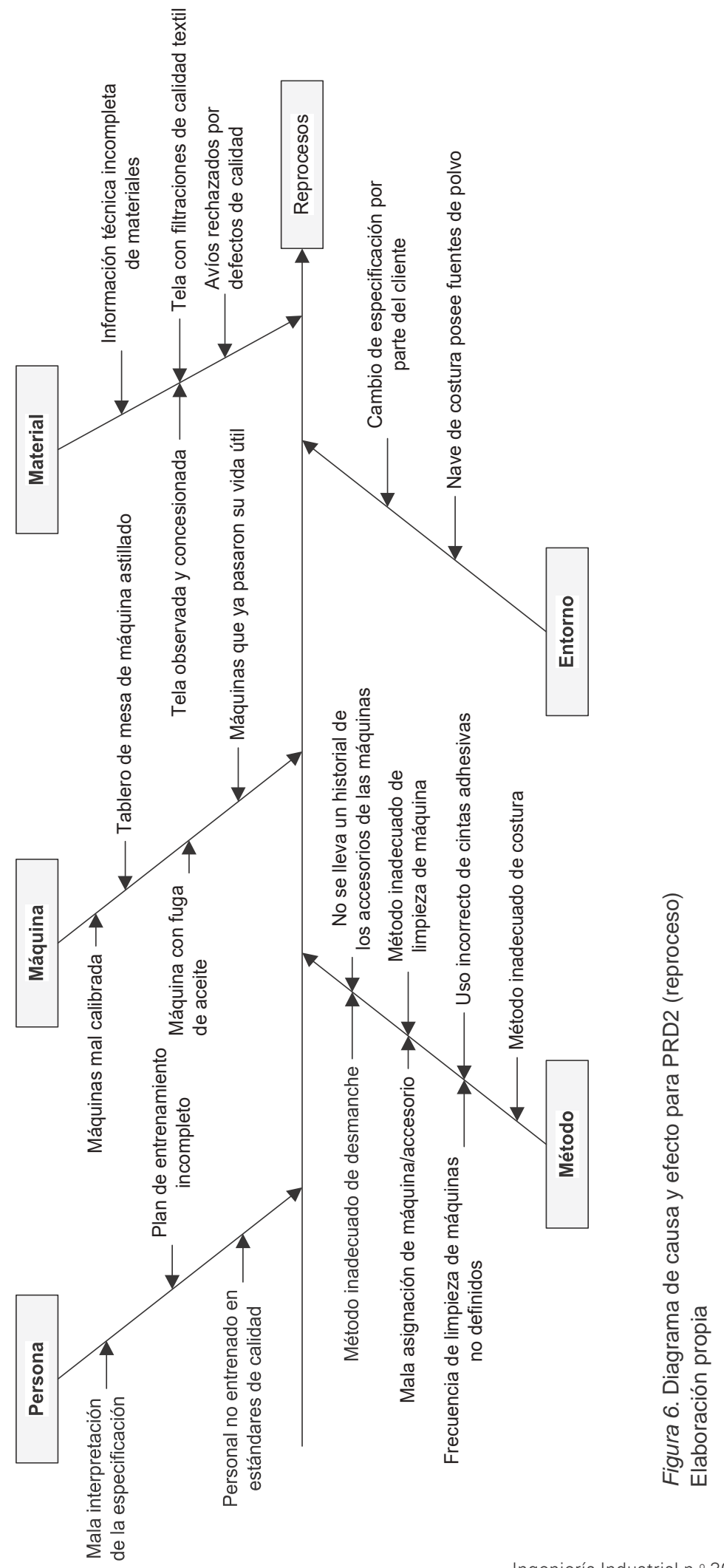

Ingeniería Industrial n. ${ }^{\circ}$ 36, 2018 
Del resumen de la tabulación, se obtuvo el siguiente diagrama de Pareto:

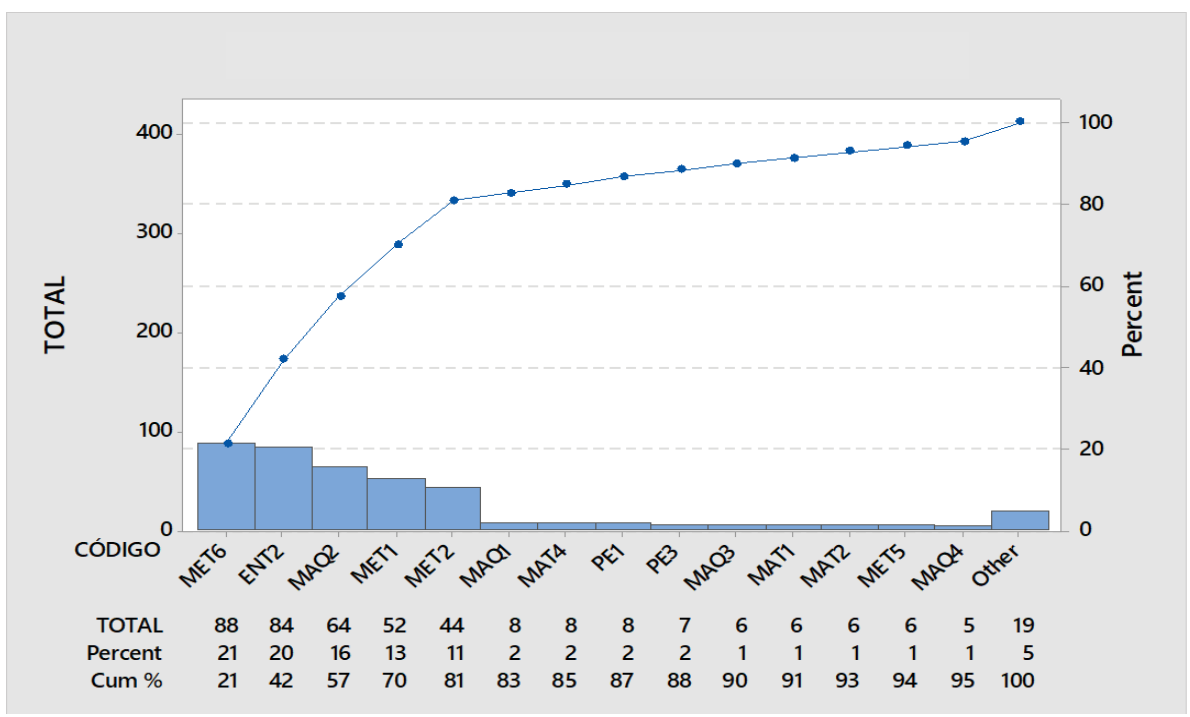

Figura 7. Diagrama de Pareto de causas - PRD2 Elaboración propia

Se puede observar que las principales causas raíces son MET6, ENT2, MAQ2, MET1 y MET2, las cuales corresponden a uso incorrecto de cintas adhesivas, nave de costura posee fuentes de polvo, tablero astillado, método inadecuado de desmanche y método inadecuado de limpieza de máquina, las cinco con un porcentaje acumulado del $81 \%$ de participación como causas del problema principal. En conclusión, del análisis de causas y efectos de las principales interferencias (ING5 y PRD2), se obtienen sus causas raíces (figura 8).

Por lo tanto, se determinó medir el tiempo de duración de las principales interferencias con el uso de técnicas de cronometraje mediante su registro en planta durante el periodo de un mes, y se limitará solo a los días de cambio de estilo, ya que el mayor número de interferencias son asociadas a esos días. Un cambio de estilo es el proceso por el cual un módulo de costura pasa de coser un producto a otro con diferentes especificaciones técnicas. 
Mejora en la eficiencia y en el ambiente de trabajo en Texgroup S.A.
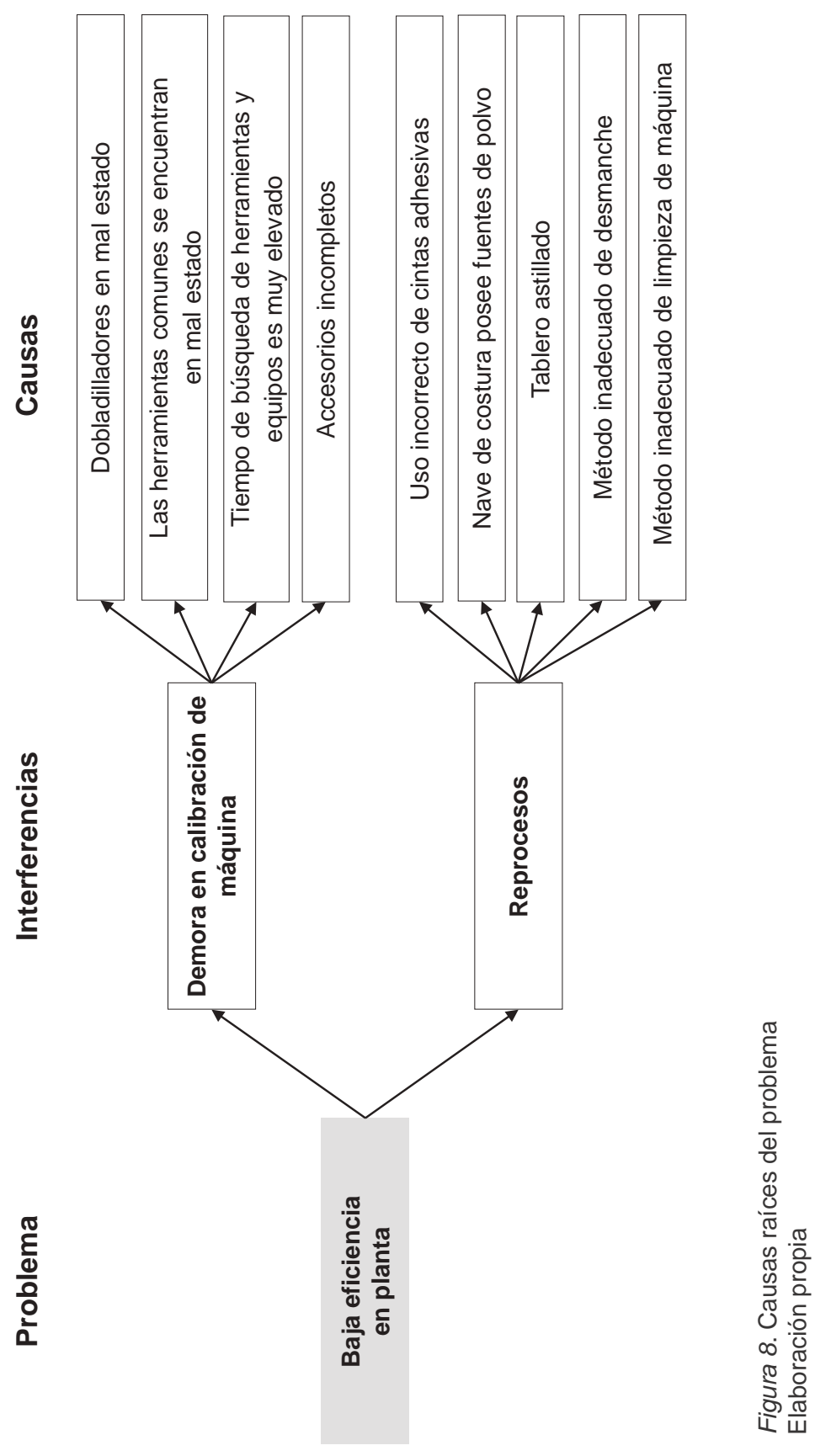
El registro iniciaba cuando el observador detectaba la ocurrencia con los tiempos de inicio y fin. Por ejemplo:

- Interferencia: Calibración de máquina.

Inicio: Momento en el que el operario manifestaba que la máquina no estaba cosiendo de la forma correcta.

Fin: Momento en el que el operario comenzaba a coser en la máquina calibrada.

Para realizar la medición de las interferencias, se observó un cambio de estilo por día y por módulo durante un mes. Se obtuvieron 21 observaciones, dentro de las cuales cada módulo fue observado por lo menos una vez.

De la medición de duración de interferencias, se obtuvo lo siguiente (se ha considerado una observación por módulo) (véase tabla 11).

Para el registro de datos, el observador anotaba en qué operación de la línea ocurría la interferencia, ya que, al ser un sistema modular, es importante identificar en qué parte del flujo ocurre. Por ejemplo: la interferencia ocurrió en la máquina cerradora de costados (operación 12), es decir, que desde la operación 13 hasta la última operación el flujo se detiene, por lo que el tiempo de una interferencia es la suma de todos los tiempos perdidos desde la operación 12 hasta la última.

Al finalizar la recopilación de datos, se procedió a elaborar un resumen de minutos perdidos y el posible incremento de eficiencia si las interferencias se redujeran en $25 \%$, 50 \% y $75 \%$ (véase tabla 12).

De la tabla se observa que, al reducir las interferencias en una cuarta parte, una mitad o mayor proporción, se obtiene un beneficio de incremento de eficiencia.

Si consideramos que durante el 2014 la planta produjo 81364,500 minutos con una eficiencia anual de $62 \%$, así como el incremento de $1 \%$ de eficiencia mediante la reducción en $25 \%$ de las principales interferencias analizadas, se hubieran producido 82 676,831 minutos. Esta diferencia al valor de venta de cada minuto producido generaría un incremento del ingreso en aproximadamente USD 129 000, monto que sería trasladado directamente al beneficio, pues no se incurriría en mayor gasto al usarse los mismos recursos. 
Mejora en la eficiencia y en el ambiente de trabajo en Texgroup S.A.

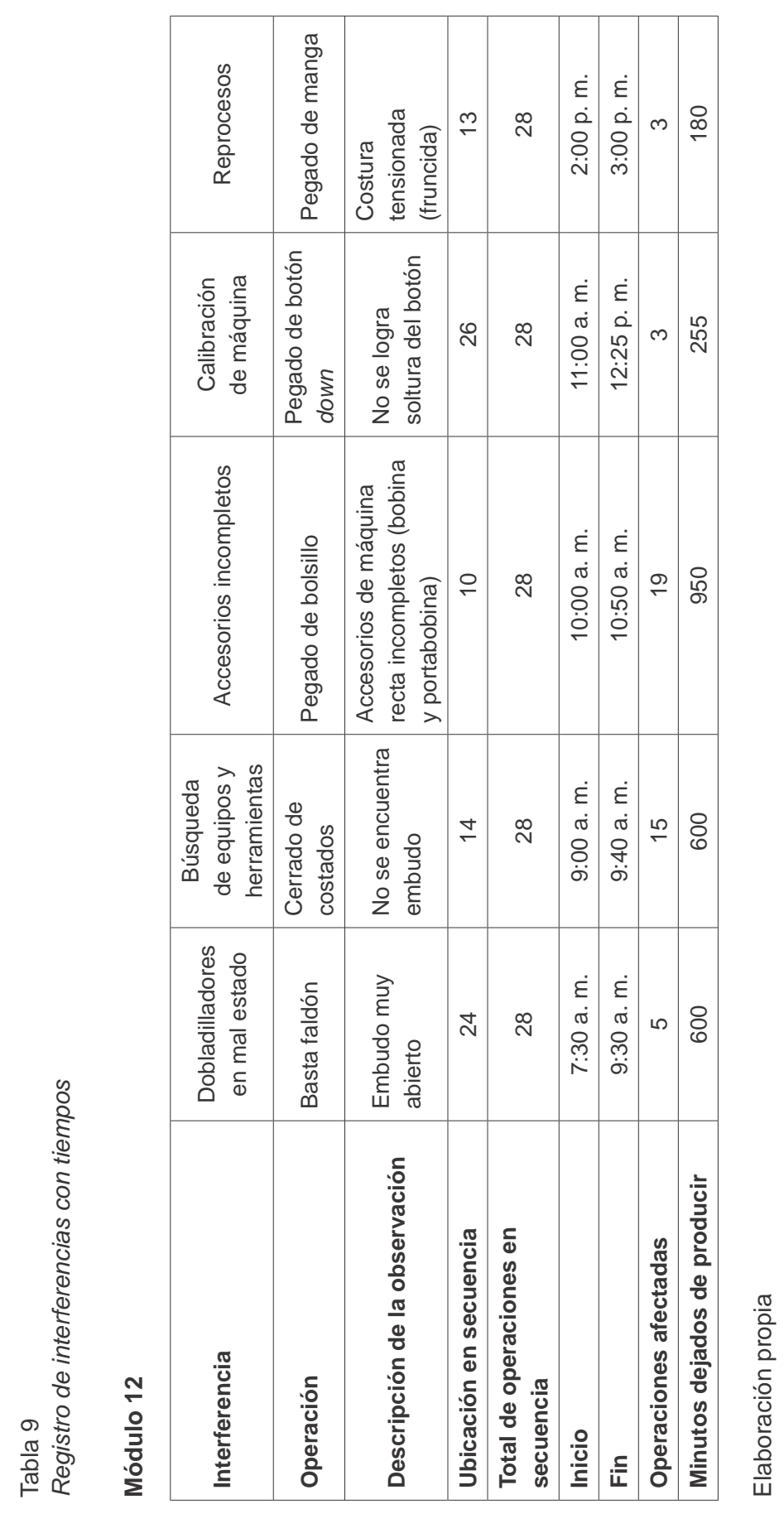




\begin{tabular}{|c|c|c|c|c|c|c|c|c|c|c|c|c|}
\hline 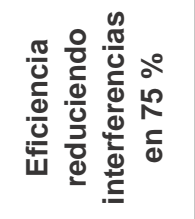 & $\begin{array}{l}\stackrel{0}{ } \\
\text { ָิ }\end{array}$ & $\begin{array}{l}\stackrel{0}{\circ} \\
\hat{0}\end{array}$ & $\begin{array}{l}\circ \\
0 \\
0\end{array}$ & $\begin{array}{l}\stackrel{0}{\circ} \\
\forall\end{array}$ & $\begin{array}{l}\circ \\
8 \\
8\end{array}$ & $\frac{0}{10}$ & $\begin{array}{l}\circ \\
\circ \\
\infty \\
\infty\end{array}$ & $\begin{array}{l}\circ \\
0 \\
6 \\
10\end{array}$ & $\frac{\circ}{6}$ & $\begin{array}{l}\circ \\
\hat{\sigma}\end{array}$ & $\begin{array}{l}\circ \\
0 \\
\infty \\
+\end{array}$ & $\begin{array}{l}\stackrel{0}{0} \\
\text { L̊ }\end{array}$ \\
\hline 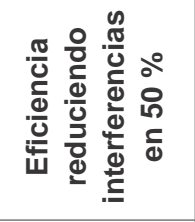 & 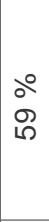 & $\begin{array}{l}\text { ○̊ } \\
10 \\
0\end{array}$ & $\begin{array}{l}\circ \\
\circ \\
\infty \\
\infty\end{array}$ & $\begin{array}{l}\partial^{\circ} \\
\text { m }\end{array}$ & $\begin{array}{l}\circ \\
0 \\
\infty \\
\infty\end{array}$ & $\begin{array}{l}0^{\circ} \\
0 \\
0\end{array}$ & $\begin{array}{l}\circ \\
0 \\
0 \\
1\end{array}$ & $\begin{array}{l}\circ \\
\text { ¿े } \\
\text { Lे }\end{array}$ & 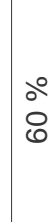 & $\begin{array}{l}\circ \\
0 \\
0 \\
\mathscr{0}\end{array}$ & $\begin{array}{l}\stackrel{0}{\circ} \\
\text { 字 }\end{array}$ & $\begin{array}{l}{ }^{\circ} \\
\text { Lे }\end{array}$ \\
\hline 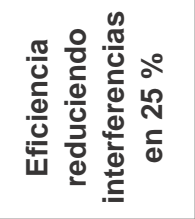 & $\begin{array}{l}\stackrel{0}{\circ} \\
\hat{1}\end{array}$ & 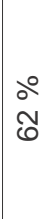 & $\begin{array}{l}\stackrel{0}{0}^{\circ} \\
\text { 字 }\end{array}$ & $\frac{\partial}{\gamma}$ & $\begin{array}{l}\stackrel{0}{\circ} \\
\text { in }\end{array}$ & $\begin{array}{l}\circ \\
\stackrel{9}{+}\end{array}$ & $\begin{array}{l}\circ 0 \\
\stackrel{\circ}{n}\end{array}$ & $\begin{array}{l}\circ \\
\text { مొ } \\
\text { గ̂ }\end{array}$ & $\begin{array}{l}\circ \\
\circ \\
\infty \\
\infty\end{array}$ & $\begin{array}{l}\circ \\
0 \\
\mathscr{0}\end{array}$ & $\begin{array}{l}\circ \\
0 \\
\dot{+}\end{array}$ & $\begin{array}{l}\stackrel{0}{\circ} \\
\text { ஸ̂ }\end{array}$ \\
\hline 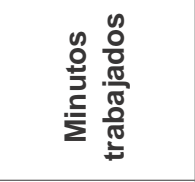 & $\frac{\stackrel{\infty}{N}}{\stackrel{\sim}{\omega}}$ & $\begin{array}{l}\infty \\
0 \\
0 \\
0 \\
0\end{array}$ & $\begin{array}{l}\mathscr{O} \\
\stackrel{8}{0} \\
\cong\end{array}$ & $\begin{array}{l}\text { \& } \\
\infty \\
\stackrel{\infty}{N}\end{array}$ & $\begin{array}{l}\infty \\
\stackrel{\infty}{\sim} \\
\stackrel{m}{\leftarrow}\end{array}$ & $\begin{array}{l}\mathscr{D} \\
\stackrel{8}{ } \\
\stackrel{-}{-}\end{array}$ & $\begin{array}{l}\text { \& } \\
\text { ه } \\
\text { 으 }\end{array}$ & $\begin{array}{l}\stackrel{\infty}{N} \\
\underset{\sigma}{\omega} \\
\underline{0}\end{array}$ & $\begin{array}{l}\text { 오 } \\
\text { గn } \\
\mp\end{array}$ & $\begin{array}{l}\infty \\
0 \\
0 \\
0 \\
0\end{array}$ & $\begin{array}{l}\mathscr{D} \\
\text { O } \\
\stackrel{N}{-}\end{array}$ & 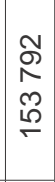 \\
\hline 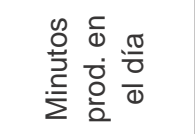 & $\begin{array}{l}\text { P } \\
\underset{\infty}{\infty}\end{array}$ & $\overline{\widetilde{N}}$ & 导 & 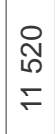 & $\begin{array}{l}\mathscr{\infty} \\
\stackrel{\infty}{N}\end{array}$ & $\begin{array}{l}\mathscr{L} \\
\infty \\
\infty \\
i\end{array}$ & 웅 & $\begin{array}{l}\widehat{\infty} \\
\infty \\
\infty\end{array}$ & $\begin{array}{l}0 \\
0 \\
0 \\
0 \\
0\end{array}$ & 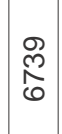 & 守 & $\frac{N}{\infty}$ \\
\hline 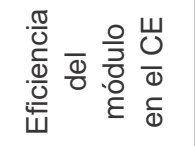 & $\begin{array}{l}\circ 0 \\
\text { L }\end{array}$ & $\begin{array}{l}\circ \\
0 \\
0\end{array}$ & $\begin{array}{l}\partial^{\circ} \\
\text { L }\end{array}$ & $\begin{array}{l}\check{o}^{\circ} \\
\text { 웅 }\end{array}$ & $\begin{array}{l}\check{O}^{\circ} \\
2 \\
\llcorner\end{array}$ & $\begin{array}{l}\circ \\
\circ \\
\infty \\
\infty\end{array}$ & $\begin{array}{l}\circ \\
\text { Lे }\end{array}$ & \begin{tabular}{l}
$\circ$ \\
\multirow{N}{N}{} \\
N
\end{tabular} & 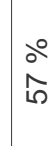 & $\begin{array}{l}\circ \\
0 \\
\llcorner \\
0\end{array}$ & $\begin{array}{l}\partial^{\circ} \\
\text { L }\end{array}$ & $\frac{\circ}{i n}$ \\
\hline 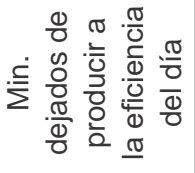 & $\underset{\mathfrak{N}}{\stackrel{\Upsilon}{\leftarrow}}$ & $\bar{\infty}$ & 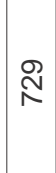 & $\begin{array}{l}0 \\
0 \\
0 \\
0\end{array}$ & 今 & 艿 & $\frac{N}{5}$ & $\bar{\infty}$ & $\begin{array}{l}L \\
\infty \\
\infty \\
\circ\end{array}$ & 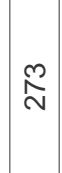 & 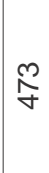 & 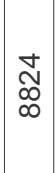 \\
\hline 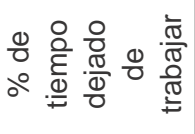 & $\begin{array}{l}0 \\
0 \\
0 \\
0 \\
0\end{array}$ & 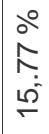 & $\begin{array}{l}0 \\
0 \\
\infty \\
m \\
\rho \\
\Gamma\end{array}$ & 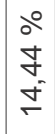 & $\begin{array}{l}00 \\
0 \\
0 \\
E \\
E\end{array}$ & $\begin{array}{l}0 \\
0 \\
0 \\
0 \\
1\end{array}$ & $\begin{array}{l}\circ \\
0 \\
0 \\
0 \\
0^{\circ}\end{array}$ & $\begin{array}{l}\circ \\
\frac{0}{m} \\
\sigma \\
\sigma\end{array}$ & $\begin{array}{l}\circ \\
\text { ○े } \\
\sigma^{\circ}\end{array}$ & $\begin{array}{l}\circ \\
0 \\
0 \\
0 \\
f\end{array}$ & $\begin{array}{l}0^{0} \\
\stackrel{0}{0} \\
\infty^{\circ}\end{array}$ & 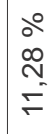 \\
\hline 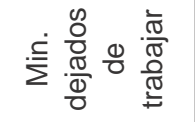 & $\begin{array}{l}\stackrel{\llcorner}{\infty} \\
\stackrel{\leftrightarrow}{\sim}\end{array}$ & $\begin{array}{l}\stackrel{1}{0} \\
0 \\
0\end{array}$ & $\frac{9}{6}$ & 兽 & $\begin{array}{l}\hat{\mathscr{O}} \\
\leftarrow\end{array}$ & 守 & $\stackrel{\infty}{\sigma}$ & 둥 & ڤ્ & $\underset{\sim}{\stackrel{\sim}{\sim}}$ & Nิ & 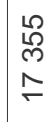 \\
\hline $\begin{array}{l}\frac{0}{3} \\
\frac{0}{0} \\
\frac{0}{2}\end{array}$ & $\stackrel{\sim}{\sim}$ & $\stackrel{m}{-}$ & $\underset{\square}{ }$ & $\stackrel{2}{2}$ & $\stackrel{\wedge}{=}$ & $\stackrel{\infty}{-}$ & $\stackrel{0}{\square}$ & 尺 & $\bar{N}$ & N & ஓి & 要 \\
\hline
\end{tabular}

$\frac{\pi}{0}$
$\frac{0}{0}$
$\overline{0}$
$\frac{0}{0}$
$\frac{\pi}{0}$
$\frac{\pi}{0}$
$\frac{0}{\pi}$
$\frac{\pi}{w}$ 


\title{
PASO 4: Establecer nivel exigido
}

\section{Determinación de las alternativas de solución}

\author{
A continuación, se muestra una tabla de alternativas de soluciones para \\ cada problema encontrado en el punto anterior.
}

\section{Tabla 11}

\section{Propuestas de solución}

\begin{tabular}{|c|c|c|c|c|}
\hline Interferencia & Causa & Propuesta & Justificación & Impacto \\
\hline \multirow{3}{*}{$\begin{array}{l}\text { Calibración } \\
\text { de máquina }\end{array}$} & $\begin{array}{l}\text { Dobladilladores } \\
\text { en mal estado }\end{array}$ & $\begin{array}{l}\text { Reparar los } \\
\text { dobladilladores que } \\
\text { aún pueden ser } \\
\text { reutilizados; caso } \\
\text { contrario, reponer los } \\
\text { que se encuentran } \\
\text { deteriorados. }\end{array}$ & $\begin{array}{l}\text { Para reproducir una operación } \\
\text { de costura a nivel industrial, es } \\
\text { imprescindible para algunas } \\
\text { operaciones el uso de dobladilladores } \\
\text { (embudos), los cuales deben } \\
\text { encontrarse en buen estado, ya que } \\
\text { se rigen a parámetros de ingreso } \\
\text { de tela, doblez a medida y salida } \\
\text { de las costuras. Además, estos } \\
\text { dobladilladores podrán ser instalados } \\
\text { en las máquinas rápidamente si se } \\
\text { encuentran en buen estado. }\end{array}$ & $\begin{array}{l}\text { Garantizar la } \\
\text { disponibilidad de los } \\
\text { dobladilladores en buen } \\
\text { estado junto con el } \\
\text { aseguramiento de las } \\
\text { costuras en formas y } \\
\text { medidas correctas. }\end{array}$ \\
\hline & $\begin{array}{l}\text { Las herramientas } \\
\text { comunes se } \\
\text { encuentran } \\
\text { desordenadas }\end{array}$ & $\begin{array}{l}\text { Asignar un lugar para } \\
\text { las herramientas } \\
\text { comunes, } \\
\text { organizarlas de } \\
\text { acuerdo con la } \\
\text { frecuencia de uso y } \\
\text { establecer el método } \\
\text { de uso y devolución. }\end{array}$ & $\begin{array}{l}\text { Las herramientas de uso común } \\
\text { son aquellas que posee el área } \\
\text { de mantenimiento en cantidades } \\
\text { limitadas por su alta especialización } \\
\text { para algunas máquinas y costo; por } \\
\text { lo tanto, es necesario que estas sean } \\
\text { usadas correctamente y devueltas } \\
\text { enseguida para estar disponibles para } \\
\text { su próximo uso. }\end{array}$ & $\begin{array}{l}\text { Alargar la vida útil de las } \\
\text { herramientas y asegurar } \\
\text { su disponibilidad } \\
\text { inmediata. }\end{array}$ \\
\hline & $\begin{array}{l}\text { Tiempo de } \\
\text { búsqueda de } \\
\text { herramientas y } \\
\text { equipos es muy } \\
\text { elevado }\end{array}$ & $\begin{array}{l}\text { Utilizar un método } \\
\text { objetivo de orden } \\
\text { que permita ubicarlas } \\
\text { en función de su } \\
\text { frecuencia de uso, } \\
\text { tamaño, cantidad } \\
\text { disponible y otras } \\
\text { variables para } \\
\text { reducir su tiempo de } \\
\text { búsqueda. }\end{array}$ & $\begin{array}{l}\text { Cuando el tiempo de búsqueda es } \\
\text { excesivo, puede interferir con el } \\
\text { desenvolvimiento de las actividades } \\
\text { de producción. En la industria de la } \\
\text { confección, el uso de mano de obra } \\
\text { intensiva significa que cada operario } \\
\text { cuenta por lo menos con una máquina } \\
\text { de coser, las cuales tienen que ser } \\
\text { reguladas en función del requerimiento } \\
\text { del cliente (cantidad de puntadas, tipo } \\
\text { de puntada, tensión de la costura, } \\
\text { etc.), por lo que la disponibilidad de } \\
\text { las herramientas debe ser la mayor } \\
\text { posible. }\end{array}$ & $\begin{array}{l}\text { Elevar la disponibilidad } \\
\text { de herramientas y } \\
\text { equipos con un tiempo } \\
\text { de búsqueda reducido. }\end{array}$ \\
\hline
\end{tabular}

(continúa) 
(continúación)

\begin{tabular}{|c|c|c|c|c|}
\hline Interferencia & Causa & Propuesta & Justificación & Impacto \\
\hline \multirow{2}{*}{$\begin{array}{l}\text { Calibración } \\
\text { de máquina }\end{array}$} & $\begin{array}{l}\text { Accesorios } \\
\text { incompletos }\end{array}$ & $\begin{array}{l}\text { Reponer accesorios } \\
\text { de todas las } \\
\text { máquinas. }\end{array}$ & $\begin{array}{l}\text { Todas las máquinas de costura } \\
\text { requieren de accesorios en buen } \\
\text { estado para su funcionamiento. }\end{array}$ & $\begin{array}{l}\text { Las máquinas } \\
\text { funcionarán con las } \\
\text { medidas, tensiones y } \\
\text { presión adecuadas. } \\
\text { Además, reduce el } \\
\text { tiempo de reposición } \\
\text { cuando se acaba el hilo } \\
\text { de la(s) bobina(s) en uso. }\end{array}$ \\
\hline & $\begin{array}{l}\text { Estándar de } \\
\text { mecánicos } \\
\text { incompleto }\end{array}$ & $\begin{array}{l}\text { Completar el } \\
\text { estándar con } \\
\text { mecánicos } \\
\text { calificados. }\end{array}$ & $\begin{array}{l}\text { Los mecánicos asignados a costura } \\
\text { son limitados, es imprescindible } \\
\text { su presencia para la calibración, } \\
\text { movimiento de máquinas, reparación, } \\
\text { mantenimientos preventivos, } \\
\text { instalación de dobladilladores y } \\
\text { preparación de prensatelas. }\end{array}$ & $\begin{array}{l}\text { Reducir el tiempo } \\
\text { de preparación de } \\
\text { máquinas en el cambio } \\
\text { de estilo y su reparación. }\end{array}$ \\
\hline \multirow{3}{*}{ Reprocesos } & $\begin{array}{l}\text { Uso incorrecto } \\
\text { de cintas } \\
\text { adhesivas }\end{array}$ & $\begin{array}{l}\text { Reemplazar el uso de } \\
\text { cintas de embalaje a } \\
\text { cintas masking tape } \\
\text { de uso industrial. }\end{array}$ & $\begin{array}{l}\text { Las cintas adhesivas son usadas } \\
\text { para reforzar la instalación de un } \\
\text { dobladillador o equipo a la máquina, } \\
\text { unir piezas y pegar complementos a la } \\
\text { estación de trabajo. }\end{array}$ & $\begin{array}{l}\text { Reducir las h-h utilizadas } \\
\text { en la limpieza de } \\
\text { residuos adhesivos. }\end{array}$ \\
\hline & $\begin{array}{l}\text { Nave de costura } \\
\text { posee fuentes de } \\
\text { polvo }\end{array}$ & $\begin{array}{l}\text { Modificar el sistema } \\
\text { de inyección de aire } \\
\text { de la planta por uno } \\
\text { que tenga filtros de } \\
\text { polvo. }\end{array}$ & $\begin{array}{l}\text { Debido a la ubicación en una zona } \\
\text { industrial de la zona este de Lima, } \\
\text { la cantidad de polvo que arrastra el } \\
\text { aire es considerable, lo cual afecta } \\
\text { de manera directa a la calidad del } \\
\text { producto y al funcionamiento de los } \\
\text { equipos. }\end{array}$ & $\begin{array}{l}\text { Reducir los defectos de } \\
\text { mancha por polvo y las } \\
\text { fallas de máquina por } \\
\text { acumulación de polvo en } \\
\text { motor y ventiladores. }\end{array}$ \\
\hline & Tablero astillado & $\begin{array}{l}\text { Reemplazar y/o } \\
\text { reparar los tableros } \\
\text { astillados. }\end{array}$ & $\begin{array}{l}\text { Las estaciones de trabajo contemplan } \\
\text { el cabezal de la máquina, el tablero y } \\
\text { los acoples entre máquinas. Debido } \\
\text { al manipuleo requerido por cada } \\
\text { operación, estos tableros sufren un } \\
\text { desgaste que muchas veces llega a } \\
\text { dañar su capa de acabado y puede } \\
\text { generar defectos. }\end{array}$ & $\begin{array}{l}\text { Eliminar los efectos } \\
\text { generados por el estado } \\
\text { de tableros deteriorados. }\end{array}$ \\
\hline
\end{tabular}


(continúación)

\begin{tabular}{|c|c|c|c|c|}
\hline Interferencia & Causa & Propuesta & Justificación & Impacto \\
\hline & $\begin{array}{l}\text { Método } \\
\text { inadecuado de } \\
\text { desmanche }\end{array}$ & $\begin{array}{l}\text { Uniformizar } \\
\text { el método de } \\
\text { desmanche de } \\
\text { prendas. }\end{array}$ & $\begin{array}{l}\text { Las prendas principalmente de } \\
\text { colores claros son susceptibles a } \\
\text { manchas a causa del manipuleo entre } \\
\text { operaciones. Además, al no existir } \\
\text { almacenes de tránsito en el área de } \\
\text { corte, las piezas están expuestas a la } \\
\text { espera de su despacho a costura. }\end{array}$ & $\begin{array}{l}\text { Reducir el tiempo y } \\
\text { asegurar la efectividad } \\
\text { del desmanche. }\end{array}$ \\
\hline Reprocesos & $\begin{array}{l}\text { Método } \\
\text { inadecuado } \\
\text { de limpieza de } \\
\text { máquina }\end{array}$ & $\begin{array}{l}\text { Establecer el método } \\
\text { correcto de limpieza } \\
\text { de máquinas de } \\
\text { acuerdo con la } \\
\text { frecuencia de uso, } \\
\text { tipo de cabezal, tipo } \\
\text { de motor, tipo de } \\
\text { máquina y las zonas } \\
\text { donde tenga contacto } \\
\text { el tejido. }\end{array}$ & $\begin{array}{l}\text { Alrededor del } 60 \% \text { de defectos } \\
\text { registrados por calidad, como } \\
\text { manchas, se debe a lubricantes como } \\
\text { aceite o grasa. }\end{array}$ & $\begin{array}{l}\text { Reducir en por lo menos } \\
75 \% \text { los defectos por } \\
\text { manchas de lubricantes. }\end{array}$ \\
\hline
\end{tabular}

Elaboración propia

De las propuestas revisadas, su justificación e impacto, se llegó a tres alternativas de solución:

- Generar un programa de reposición inmediata para herramientas, complementos, acoples y equipos con mal funcionamiento, el cual considere stocks para atención de cada evento.

- Implementar un programa de 5S en la planta de Texgroup, el cual permita reducir las interferencias asociadas al orden y la limpieza con el fin de elevar la eficiencia operativa.

- Tomando en cuenta el estado actual de la maquinaria, dobladilladores, accesorios y equipos, efectuar un mantenimiento y/o cambiar aquellos que lo requieran y dejarlos $100 \%$ operativos.

\section{PASO 5: Definir y programar las soluciones}

\section{Evaluación y selección de la mejor alternativa}

De las alternativas de solución propuestas en el punto anterior, se ha elaborado una escala de valoración por puntos en función de criterios que se detallan a continuación: 
- Costo: que es el valor monetario estimado de la implementación de la mejora. Incluye costos aproximados de equipos, personal, asesorías, etcétera. Se han establecido tres escalas de puntuación: de USD 0 a 10 000: 6 puntos; de USD 10 001-25 000: 4 puntos; y de USD 25 001-35 000: 2 puntos.

- Tiempo de implementación: que es el tiempo estimado desde la aprobación de la mejora por parte de la gerencia hasta la culminación al $100 \%$ del plan de actividades asociado a la mejora, además de la entrega de resultados como memorias e informes. Se han establecido tres escalas de puntuación: de 0 a 6 meses: 6 puntos, de 6 a 12 meses: 4 puntos, y más de 12 meses: 2 puntos.

- Vigencia: que es la duración el resultado positivo de la implementación en el tiempo. Se han establecido tres escalas de puntuación: más de 24 meses: 6 puntos, de 12 a 24 meses: 4 puntos, y de 0 a 12 meses: 2 puntos.

- Impacto: que es el resultado a nivel cuantitativo y cualitativo de la mejora en la organización, al contemplar los beneficios directos e indirectos de la aplicación del cambio en las formas de trabajo y métodos con un resultado exitoso. Está relacionado con la vigencia del resultado de la implementación. Se han establecido tres escalas de puntuación: alto: 6 puntos, medio: 4 puntos, y bajo: 2 puntos.

Para calificar las alternativas, se diseñó la siguiente tabla (tabla 14), y se elegirá como la mejor alternativa de solución la que tenga mayor puntaje total.

\section{Evaluación del alcance y limitaciones de la solución propuesta}

Luego de elegir en el punto anterior a la implementación de un programa de $5 \mathrm{~S}$ en la planta de Texgroup como la mejor solución, se han evaluado el alcance y sus limitaciones.

Para el alcance se ha decido que, por ser necesaria la inclusión de la filosofía 5S como parte de la cultura de la organización, este debe ser amplio y abarcar a todas las operaciones de la compañía.

Por otro lado, las limitaciones se describen en la siguiente tabla (tabla 15) y obedecen principalmente a factores presupuestales y de entrenamiento del personal. 
Mejora en la eficiencia y en el ambiente de trabajo en Texgroup S.A.

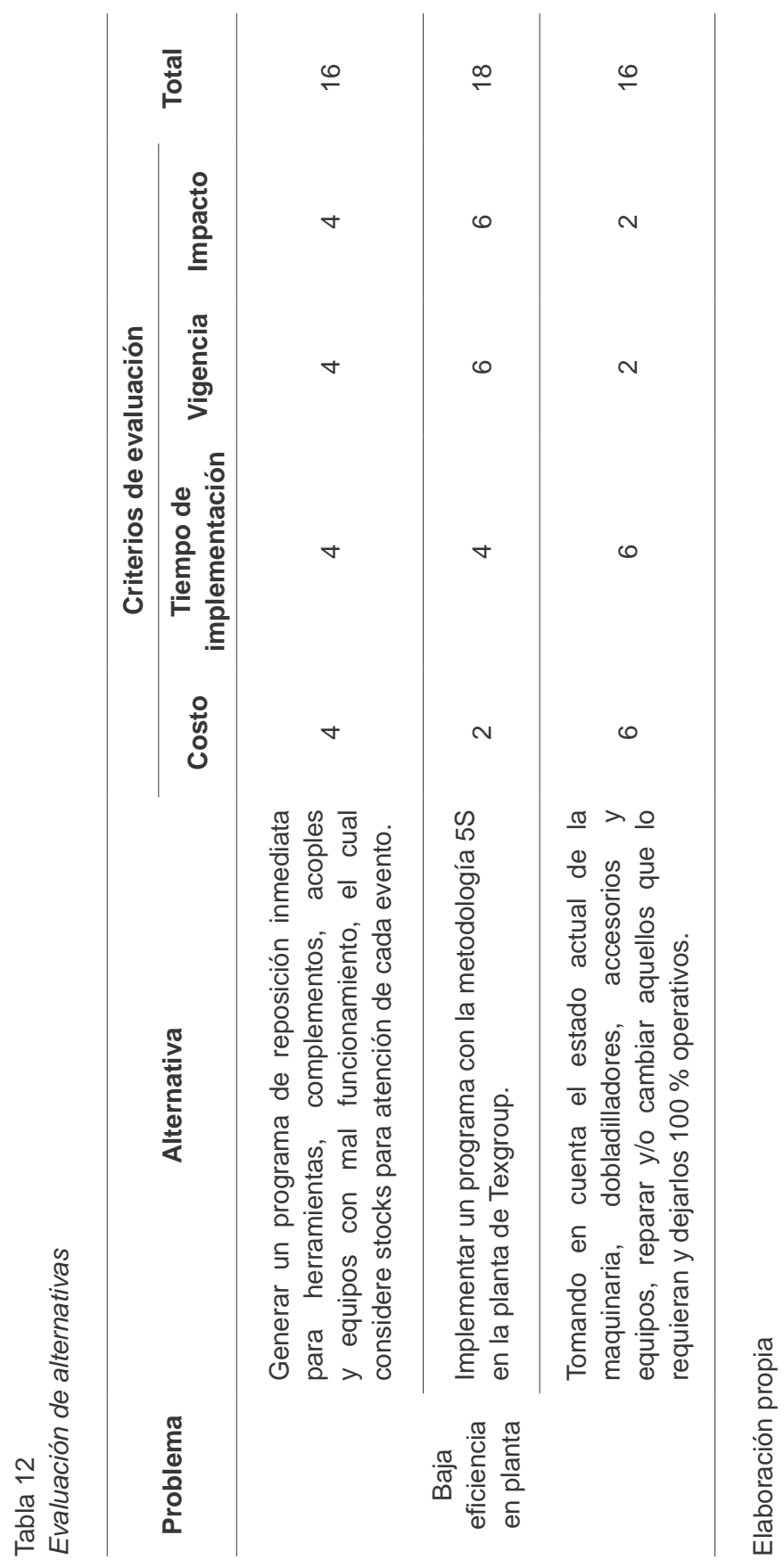


Tabla 13

Solución propuesta

\begin{tabular}{|c|c|c|}
\hline Solución propuesta & Alcance & Limitaciones \\
\hline $\begin{array}{l}\text { Implementar un } \\
\text { programa con la } \\
\text { metodología } 5 \text { s en la } \\
\text { planta de Texgroup. }\end{array}$ & $\begin{array}{l}\text { Áreas productivas } \\
\text { y administrativas } \\
\text { de la compañía. }\end{array}$ & $\begin{array}{l}\text { Disponibilidad de recursos aprobados } \\
\text { por la GG, rotación de personal, diversos } \\
\text { grados de instrucción y conocimientos en } \\
\text { el personal operario. Disponibilidad de } \\
\text { líderes de la empresa para la ejecución del } \\
\text { plan de trabajo. }\end{array}$ \\
\hline
\end{tabular}

Elaboración propia

PASO 6: Implantar y verificar las soluciones

Implementación de la solución

Llegados a este punto, las etapas del proyecto son las siguientes:

(1)

\begin{tabular}{|l|}
\hline \multicolumn{1}{|c|}{ Planear } \\
\hline $\begin{array}{c}\text { Determinar y obtener el } \\
\text { compromiso de la dirección. }\end{array}$ \\
\hline $\begin{array}{l}\text { Presentación oficial del proyecto } \\
\text { 5S con los jefes y coordinadores } \\
\text { de área. }\end{array}$ \\
\hline $\begin{array}{l}\text { Recopilación de información de } \\
\text { las 5S. }\end{array}$ \\
\hline Capacitación al equipo de trabajo \\
\hline
\end{tabular}

(2)

\begin{tabular}{l} 
Hacer \\
\hline $\begin{array}{l}\text { Comunicación del inicio del } \\
\text { proyecto a la organización por } \\
\text { parte del líder. }\end{array}$ \\
\hline
\end{tabular}

Inicio de la difusión al personal.

Figura 9. Etapas de la implementación

Elaboración propia

(3)

(4)

\begin{tabular}{|l|l|}
\hline \multicolumn{1}{|c|}{ Verificar } & Actuar \\
\hline $\begin{array}{l}\text { Análisis de la información } \\
\text { recabada. }\end{array}$ & Clasificar \\
\hline $\begin{array}{l}\text { Generación del cronograma } \\
\text { general de la implementación. }\end{array}$ & Ordenar \\
\hline & Limpiar \\
\hline & Pstandarizar \\
\hline
\end{tabular}




\section{PASO 7: Acciones de garantía}

En este caso, la solución elegida -un programa de $5 \mathrm{~S}$ - cuenta con su propia herramienta de preservación del cambio en la quinta S: Shitsuke. Además, es imprescindible generar mecanismos e indicadores de proceso que permitan medir la efectividad de la mejora, los cuales deben ser fáciles de calcular y útiles para la toma de decisiones del equipo gerencial.

En la ejecución del mencionado programa, se usaron los siguientes indicadores: eficiencia en los días de cambio de estilo y razón porcentual entre el número de reprocesos por manchas de tierra, aceite y grasa y reprocesos totales. Y mecanismo: auditorías 5S.

\section{CONCLUSIONES}

Del trabajo de investigación se concluye lo siguiente:

- La mejora de los métodos de trabajo, incluidos los factores relacionados con el orden y la limpieza, genera un beneficio integral tanto en el tiempo de la operación como en su éxito (éxito se entiende como un producto conforme).

- Para validar que la inversión en una implementación de 5S representaba una oportunidad económicamente atractiva para Texgroup, se realizaron mediciones para cuantificar el impacto negativo que actualmente tienen los problemas identificados como principales. Con esto se pudo simular el beneficio en tres escenarios: pesimista, conservador y optimista.

- Las herramientas para el estudio fueron: diagramas de Pareto, histogramas, diagramas de causa-efecto, VSM, DOP, Sedac, las cuales demostraron su efectividad para cuantificar y estratificar la información que podía parecer subjetiva antes del análisis.

\section{REFERENCIAS}

Aminul Haque, K., Chowdhury, S., y Shahwath, A. (2014). Implementation of $5 \mathrm{~s}$ and its effect in a selected garments factory: A case study. Bangladesh Research Publications Journal, X, 291-297.

Castillo, M. V. (2009). Desarrollo de una metodología para mejorar la productividad del proceso de fabricación de puertas de madera. Guayaquil: Escuela Superior Politécnica del Litoral. 
Desta, A. (2014). Analysis of Kaizen Implementation in Northern Ethiopia's Manufacturing Industries. International Journal of Business and Commerce, III, 39-57.

Guachisaca Guerrero, C. A. (2009). Implementación de 5S como una metodología de Mejora en una empresa de elaboración de pinturas. Guayaquil: Escuela Superior Politécnica del Litoral.

Khan, A. M. (2013). Application of 5S System in the Sample Section of an Apparel Industry for Smooth Sample Dispatch. Research Journal of Management Sciences, II, 28-32.

Khatun, M. M. (2013). Application of industrial engineering technique for better productivity garments production. International Journal of Science, Environment and Technology, II, 1361-1369.

Paneru, N. (s. f.). Implementation of lean manufacturing tools in garment manufacturing process focusing sewing section of Men's Shirt. Degree Programme in Industrial Management. Oulu University of Applied Sciences, Oulu.

Zerón, S. I. (s. f.). Implementación de la herramienta de calidad de las 5 "S" en la empresa "Confecciones Ruvinni” ubicada en Zacualtipán, HGO. Procesos de Producción. Universidad Tecnológica de la Sierra Hidalguense, Zacualtipán de Ángeles. 